\title{
A INSERÇÃO DO BRASIL NA POLÍTICA INTERNACIONAL DE DIREITOS HUMANOS DA PESSOA IDOSA
}

\author{
Maria Helena de Aguiar Notari e Maria Helena J. M. de Macedo Fragoso
}

BRAZILIAN INSERTION IN THE INTERNATIONAL POLITICS OF AGEING PEOPLE HUMAN RIGHTS

\section{RESUMO}

ESTE ARTIGO PROPÕE-SE A ESTUDAR A EVOLUÇÃO DA PROTEÇÃO INTERNACIONAL DOS DIREITOS HUMANOS DA PESSOA IDOSA E A POSIÇÃO DO BRASIL NAS DISCUSSÕES SUB-REGIONAIS, REGIONAIS E MULTILATERAIS QUE OCORREM NA ATUALIDADE, CONSIDERANDO O PRESENTE CONTEXTO MUNDIAL DE ENVELHECIMENTO DA POPULAÇÃO E OS NOVOS DESAFIOS QUE ESSA REALIDADE IMPLICA. PALAVRAS-CHAVE

Direitos humanos; Convenção internacional; Pessoa idosa.

\section{ABSTRACT}

DUE THE EFFECT OF AGING AT THE WORLD POPULATION AND THE NEW CHALLENGES THAT THIS NEW REALITY IMPLIES, THIS ARTICLE HAS THE OBJECTIVE TO STUDY THE EVOLUTION OF THE INTERNATIONAL Protection of Ageing People human Rights and also the BRAZILIAN GOVERNMENT POSITION AT THE CONTEMPORARY SUBREGIONALS, REGIONAL AND MULTILATERAL DISCUSSIONS.

KEYWORDS

HUMAN RIGHTS; INTERNATIONAL CONVENTION; AgEING PEOPLE.

\section{INTRODUÇÃO}

O Poder Executivo brasileiro entende que os direitos da pessoa idosa devem receber tratamento de direitos humanos, por tratar-se de direitos de um grupo vulnerável. Isso foi evidenciado na criação, em 2009, da Coordenação Geral dos Direitos do Idoso (CGDI), subordinada ao Departamento de Promoção dos Direitos Humanos, da Subsecretaria de Promoção e Defesa dos Direitos Humanos, da Secretaria de Direitos Humanos da Presidência da República, e na inclusão da temática do idoso no Terceiro Plano Nacional de Direitos Humanos (PNDH-3, 2009), o qual estabelece a valorização da pessoa idosa e a promoção de sua participação na sociedade como objetivo estratégico. ${ }^{1}$

Ainda que a temática da pessoa idosa tenha ganhado institucionalização com a criação da CGDI, ao substituir o Programa de Promoção e Defesa dos Direitos da Pessoa Idosa, vigente desde 2008, como ação finalística da Secretaria de Direitos Humanos, 
prevista no Plano Plurianual de 2008-2011, ${ }^{2}$ percebe-se que a temática recebe tratamento diferenciado daquele atribuído aos Direitos Humanos das Crianças e dos Adolescentes e das Pessoas com Deficiência, que têm suas políticas administradas por subsecretarias próprias.

Isso não significa que a temática da pessoa idosa seja de menor relevância, mas que é demanda recente da população brasileira e relaciona-se à maior expectativa de vida alcançada no Brasil e no mundo todo, ainda que de maneira diferenciada de acordo com níveis de desenvolvimento socioeconômico. Um artigo do jornal O Globo confirma isso:

... uma revolução de idosos segue o seu curso. Os novos velhos exercem a cidadania, votam, são produtores e consomem. Atuam, representam, circulam, decidem, participam e agem. Por enquanto, constituem modesta força de trabalho, mas logo estarão no patamar dos novos velhos dos países centrais e vão ser uma formidável massa populacional quando a imensa população de baby boomers entrar nessa nova velhice. Por isto, envelhecimento global será uma expressão-chave para os próximos anos. ${ }^{3}$

Tendo em conta o novo contexto mundial acerca do envelhecimento e os novos desafios que essa realidade implica, este artigo propõe-se a estudar a evolução da proteção internacional dos direitos humanos da pessoa idosa e a posição do Brasil nas discussões sub-regionais, regionais e multilaterais que ocorrem na atualidade.

\section{O ENVELHECIMENTO DA POPULAÇÃO NO MUNDO}

$\mathrm{O}$ envelhecimento da população mundial não possui precedentes e tende a evoluir com o decorrer do tempo. Durante o século XX, a proporção de pessoas idosas aumentou e, muito provavelmente, essa tendência se manterá durante o século XXI. Ao fim de 2007, 10,8\% da população mundial possuía 60 anos ou mais. Projeta-se, para o ano de 2025, que a porcentagem de pessoas idosas alcance 15,1\% e que, em 2050, chegue a $21,7 \%{ }^{4}$

De acordo com o relatório Envelhecimento da População no Mundo, 2009, das Nações Unidas:

Population ageing is unprecedented, a process without parallel in the history of humanity. A population ages when increases in the proportion of older persons (that is, those aged 60 years or over) are accompanied by reductions in the proportion of children (persons under age 15) and then by declines in the proportions of persons in the working ages (15 to 59). At the world level, the number of older persons is expected to exceed the number of children for the first time in 2045. In the more 
developed regions, where population ageing is far advanced, the number of children dropped below that of older persons in $1998 .^{5}$

Todos os países do mundo têm experimentado mudanças na distribuição por faixa etária de suas populações. As diferenças regionais quanto à magnitude do processo de envelhecimento, contudo, são consideráveis, tendo em conta que os países se encontram em etapas distintas do processo de transição demográfica. Em 2009, 5,3\% da população da África tinha 60 anos ou mais, e 9,7\% da população da Ásia e do Pacífico tinha 60 anos ou mais. Na Oceania, 15,1\% da população era composta de pessoas idosas, enquanto na Europa a população idosa representava 21,6\% do total. 6

Apesar de a população idosa atual da África, Ásia, América Latina, Caribe e Oceania ser mais jovem do que a da Europa, segundo as projeções, essas regiões experimentarão um vertiginoso crescimento de sua população idosa no futuro, em consequência da elevada taxa de crescimento que exibe esse segmento da população. Em termos mundiais, a população de 60 anos ou mais tem uma taxa de crescimento de 2,6\%, que é mais elevada em regiões como a África (2,8\%), a Ásia (3\%), a América Latina e o Caribe $(3,4 \%) .^{7}$

Segundo estudos das Nações Unidas, em meados do século XX, o envelhecimento era um fenômeno dos países desenvolvidos. No futuro, espera-se que o envelhecimento da população nos países em desenvolvimento seja mais rápido, o que implicará menos tempo para adaptar-se às consequências desse fenômeno demográfico em um contexto de menor desenvolvimento econômico.

No caso específico da América Latina e do Caribe, tratam-se de regiões em processo de envelhecimento gradativo, mas inexorável. Em termos absolutos, entre os anos de 2000 e 2025, 57 milhões de pessoas com mais de 60 anos se somarão aos 41 milhões existentes, e entre 2025 e 2050, esse aumento será de 86 milhões. Trata-se de uma população que cresce com rapidez e com um ímpeto maior que a população jovem. A velocidade de mudança desse grupo etário será de três a cinco vezes maior que a população total nos períodos 2000-2025 e 2025-2050. De acordo com essa dinâmica, a proporção de pessoas maiores de 60 anos dentro da população total irá quadruplicar-se entre os anos de 2000 e 2025, de modo que um em cada quatro latino-americanos e caribenhos será idoso em 2025.

No Brasil, em 2007, a Pesquisa Nacional de Amostra Domiciliar (PNAD), ${ }^{8}$ realizada pelo Instituto Brasileiro de Geografia e Estatística (IBGE), revelou a existência de quase 20 milhões de idosos, correspondendo a 10,5\% do total da população. Destes, 16, 5 milhões viviam na área urbana e 3,4 milhões, na área rural. Destaca-se o número de idosos no Rio de Janeiro e em São Paulo com 1,7 milhão e 2,1 milhões, respectivamente.

Diante dessa realidade, torna-se "importante investigar se viver mais encontra paralelo com viver melhor; necessidade premente, desta feita, é repensar o envelhecimento inclusive no tocante ao suporte legal dirigido a esta categoria, a dos longevos". 9 


\section{I A BRECHA NORMATIVA}

A organização não governamental Age Concern definiu a importância da normatização internacional dos direitos humanos:

O direito internacional dos direitos humanos fornece um sistema que codifica os direitos humanos e torna-os obrigatórios. Preocupa-se, principalmente, com a relação entre o Estado e o indivíduo. O direito internacional dos direitos humanos é formado por diversos tratados, como acordos e convenções. Os tratados são conhecidos como "hard law" porque, quando um membro das Nações Unidas os ratifica, eles tornam-se juridicamente vinculativos. Isso significa que cada Estado membro tem de adaptar suas leis às normas dos tratados e introduzir políticas e programas para implementar as diferentes partes do tratado. Se o país não se adapta às normas dos tratados ou as contraria, ele infringe o tratado. ${ }^{10}$

Não existe um instrumento internacional juridicamente vinculativo que padronize e proteja os direitos das pessoas idosas. Na doutrina internacional dos direitos humanos, "a idade" é um assunto que tem sido tratado na ampla acepção de "qualquer condição social”, fazendo alusão às diferenças de idade e de gerações, mas cujo tratamento não tem sido manifestado. O argumento é que a natureza universal dos instrumentos internacionais deveria incluir os sujeitos de idade avançada. ${ }^{11}$ Conforme salienta a organização não governamental Age Concern:

... alguns direitos são mais relevantes para as pessoas de idade avançada do que para qualquer outra idade, a exemplo do direito de aposentadoria. Algumas vezes, um direito pode ser respeitado com relação às pessoas jovens, mas não ser bem protegido quando se trata das pessoas idosas, como o direito de acesso apropriado à saúde e a serviços sociais. ${ }^{12}$

Segundo um artigo da organização não governamental Helpage International:

Os mecanismos de direitos humanos regionais e internacionais existentes não são suficientes para proteger de forma satisfatória os direitos das pessoas idosas. As convenções de direitos humanos que são peremptórias estabelecem que os direitos humanos são para todos. Contudo, com exceção de uma convenção (a dos trabalhadores migrantes), a idade não é explicitada como uma razão pela qual a pessoa não deveria ser discriminada. Assim, a discriminação relacionada à idade é frequentemente negligenciada pelos direitos humanos no mundo. A falta dessa previsão explícita em instrumentos existentes de direitos humanos é chamada de uma "brecha normativa". ${ }^{13}$ 
Conforme ressalta Anna Cruz de Araújo Pereira da Silva “a Organização das Nações Unidas é, atualmente, a entidade de maior representatividade mundial a promover os Direitos Humanos e as liberdades fundamentais". ${ }^{14}$ Entretanto, não há convenções multilaterais que contemplem o idoso como tema principal. A proteção dos direitos das pessoas idosas ocorreria pela exegese dos instrumentos internacionais de direitos humanos existentes.

Na Declaração Universal dos Direitos Humanos de 1948 não se faz referência explícita às pessoas de idade, mas todos os seus artigos e disposições devem ser aplicados a toda sociedade, incluindo o grupo de 60 anos ou mais. ${ }^{15}$ O Pacto de Direitos Econômicos, Sociais e Culturais (1966) tampouco contém referência explícita aos direitos das pessoas idosas, exceto no artigo $9^{\circ}$, que trata do direito à seguridade social. Por essa razão, no ano de 1995, o Comitê do Pacto preparou o Sexto Observatório Geral que destaca: "Os Estados Parte no Pacto devem prestar atenção especial para a promoção e proteção dos direitos econômicos, sociais e culturais das pessoas idosas”. ${ }^{16}$

Outra questão importante é determinar se a discriminação por motivos de idade está proibida nos instrumentos internacionais juridicamente vinculativos. A esse respeito, e como afirmou o Pacto de Direitos Econômicos, Sociais e Culturais, no ano de 1995

... nem o Pacto nem a Declaração Universal dos Direitos Humanos faz referência explícita à idade como um dos fatores proibidos. Apesar de não se tratar de uma exclusão intencional, esta omissão se explica provavelmente pelo fato de que, quando esses instrumentos foram adotados, o problema do envelhecimento da população não era tão evidente nem tão urgente como na atualidade. ${ }^{17}$

No âmbito do Sistema Interamericano de Direitos Humanos, no final da década de 1980, foram incorporadas medidas específicas em favor das pessoas idosas. O Protocolo Adicional à Convenção Americana de Direitos Humanos, conhecido como o Protocolo de São Salvador, é, até o momento, o único instrumento vinculativo que incorpora especificamente os direitos das pessoas idosas. ${ }^{18}$ Quatorze países da região já ratificaram o Protocolo de São Salvador, e apenas oito deles promulgaram uma lei específica de proteção dos direitos das pessoas idosas. ${ }^{19}$

Quanto às Resoluções da Assembleia Geral das Nações Unidas e aos planos de ação internacionais nas Nações Unidas, existe um avanço mais amplo. No entanto, não são obrigações para os Estados, são normas gerais ou princípios, não normas jurídicas vinculativas. Apesar de os Estados poderem observar seu cumprimento, não estão legalmente obrigados. ${ }^{20}$

Conforme artigo da organização não governamental Helpage International "apesar de convenções internacionais serem peremptórias apenas a Estados que a ratificam, os 
setores privados e a opinião pública também necessitam de parâmetros para ajudá-los a oferecer serviços que respeitem os direitos dos idosos e atendam as pessoas idosas". ${ }^{21}$

\section{I.2 ANTECEDENTES}

Em 1973, a Assembleia Geral das Nações Unidas chamou a atenção dos países quanto à necessidade de proteger os direitos e o bem-estar das pessoas de idade. ${ }^{22}$ Contudo, apenas em 1982, iniciaram-se as discussões multilaterais sobre o envelhecimento, com a realização da I Conferência Internacional sobre Envelhecimento, que culminou na elaboração do Plano de Ação de Viena sobre Envelhecimento. Considerado o primeiro instrumento internacional sobre envelhecimento, esse plano tratou de políticas públicas específicas para saúde, nutrição, moradia, meio ambiente, família e bem-estar social.

Os Estados que participaram dessa Assembleia

reafirmaram sua crença de que os direitos fundamentais e inalienáveis consagrados na Declaração Universal dos Direitos Humanos se aplicam plenamente às pessoas idosas, e reconheceram que a qualidade de vida não é menos importante que a longevidade e que, em consequência, as pessoas de idade devem, na medida do possível, desfrutar no seio de suas próprias famílias e comunidades de vida plena, saudável e satisfatória e ser estimados como parte integrante da sociedade. ${ }^{23}$

O debate durante a I Conferência Internacional sobre Envelhecimento das Nações Unidas constatou a dificuldade de os governos priorizarem políticas públicas voltadas à pessoa idosa. De acordo com Anna Cruz de Araújo Pereira da Silva

o Plano de Viena registrava que os custos em programas voltados aos jovens são mais facilmente aceitos, porque são considerados investimentos no futuro; em sentido oposto, os custos destinados a idosos são percebidos como gastos - e não investimentos - a pressionar as finanças públicas. O etarismo, portanto, é oficializado ano a ano na feitura dos orçamentos governamentais. ${ }^{24}$

Mais tarde, em 1990, a Assembleia Geral das Nações Unidas "reconheceu a complexidade e rapidez do fenômeno do envelhecimento da população mundial e a necessidade de se formular uma base e um marco de referência comum para a proteção e promoção dos direitos das pessoas idosas”. ${ }^{25}$ Em 1991, as Nações Unidas instituíram uma Carta de Princípios para Pessoas Idosas, os quais se direcionaram em quatro principais eixos de ação: independência, participação, cuidados especiais e dignidade.

Em 2002, realizou-se em Madri a II Conferência Internacional sobre Envelhecimento, vinte anos depois da elaboração do Plano de Ação de Viena. Como 
resultado, foram elaborados a Declaração Política e o Plano de Ação Internacional de Madri sobre Envelhecimento (Mipaa). Esse Plano deu atenção especial à situação dos países em desenvolvimento e definiu como temas centrais a realização de todos os direitos humanos e liberdades fundamentais das pessoas idosas, seus direitos civis e políticos, e a eliminação de todas as formas de violência e discriminação contra a pessoa de idade. ${ }^{26}$

De acordo com o relatório das Nações Unidas sobre o Envelhecimento da População no Mundo, 2009:

In 1982, the United Nations adopted the International Plan of Action on Ageing at the first World Assembly on Ageing (United Nations, 1982). Then, in 1999 in its resolution 54/262, the General Assembly decided to convene the Second World Assembly on Ageing in 2002. The Second World Assembly adopted the Madrid International Plan of Action on Ageing, marking a turning point in how the world addresses the key challenge of building a society for all ages. The Plan focuses on three priority areas: older persons and development; advancing health and well-being into old age; and ensuring enabling and supportive environments. 27

O Mipaa é tido como documento reivindicatório. Segundo esse Plano, para alcançar-se o envelhecimento ativo e saudável, é necessário oferecer qualidade de vida ao indivíduo desde a mais tenra idade. Assim, os direitos do idoso são considerados em perspectiva de desenvolvimento do ser humano. Conforme Anna Cruz de Araújo Pereira da Silva

o "direito do idoso" há de ser compreendido de forma abrangente, não apenas como políticas para os maiores de 60 ou 65 anos. Sob perspectiva amplíssima - e somente assim podemos conceber "direitos" -, o "ramo" direito do idoso refere-se ao direito de envelhecer, ao direito de manterse vivo, ao direito à integração e à independência, direitos a novos padrões de mercado, consumo, trabalho e também direitos que devem ser gozados antes da velhice, para que possa o indivíduo preparar-se para a sua chegada. 28

Em janeiro de 2010, foi publicado um estudo do Comitê Consultivo do Conselho de Direitos Humanos das Nações Unidas acerca da "Necessidade de uma abordagem de direitos humanos e de um mecanismo efetivo das Nações Unidas para os direitos humanos das pessoas idosas". ${ }^{29}$ O estudo aponta para a necessidade de uma convenção internacional específica para os direitos das pessoas idosas, e recomenda que os Estados sejam incentivados a reportarem-se ao tratamento destinado às pessoas idosas em seus relatórios de direitos humanos. Por fim, refere-se à necessidade de 
estabelecer-se uma agenda de direitos humanos em que os direitos das pessoas idosas sejam discutidos.

A discussão sobre os direitos humanos das pessoas idosas não se esgota em fóruns da temática do idoso, tendo o Comitê para Eliminação de todas as formas de Discriminação contras as Mulheres um grupo de trabalho especial relativo aos diretos das mulheres idosas. ${ }^{30}$ A Convenção Internacional para Proteção dos Direitos dos Trabalhadores Migrantes e membros de suas famílias (1990), em seu artigo $7^{\circ}$, também trata da temática, ao proibir qualquer discriminação baseada em idade.

Nenhum dos documentos, no entanto, contém disposições juridicamente vinculativas. Tendo em conta a sua natureza não obrigatória, a implementação dos documentos internacionais de proteção à pessoa idosa tende a ser bastante frágil e vulnerável às prioridades e percepções políticas.

\section{3 A IMPORTÂNCIA DE UMA CONVENÇÃO INTERNACIONAL DOS DIREITOS DAS PESSOAS IDOSAS E DE UM RELATOR ESPECIAL}

São inúmeras as finalidades que ensejam a elaboração de uma Convenção Internacional de Direitos Humanos para as Pessoas Idosas. Com esse instrumento, a temática do idoso adquiriria maior visibilidade e reconhecimento, tanto nacional como internacional. Uma norma internacional vinculativa ajudaria a prevenir todo e qualquer tipo de discriminação institucional pautada na idade. Tal tipo de discriminação está presente em quase todas as sociedades e impede as pessoas idosas de alcançarem seu potencial completo e participarem de maneira igualitária em suas comunidades.

Ao fornecer uma estrutura normativa básica, a convenção ajudaria a estabelecer parâmetros para a formulação de leis nacionais, definindo de maneira clara as obrigações dos Estados-membros para com os direitos das pessoas idosas. Da mesma forma, reforçaria e complementaria os documentos internacionais sobre envelhecimento.

Os Estados-membros das Nações Unidas coletariam informações acerca das pessoas idosas para sugerir melhores práticas em políticas públicas, além de informar qualquer tipo de discriminação baseada em idade e gênero, e o impacto das múltiplas formas de discriminação na população acima de 60 anos. A convenção poderia, também, estabelecer mecanismos de reparação em relação a violações dos direitos humanos das pessoas idosas. O monitoramento da implementação dessa convenção encorajaria o diálogo entre os Estados, a sociedade civil, as ONGs, o setor privado e as pessoas idosas.

Paralelamente à convenção, o papel do relator especial para pessoas idosas seria o de coordenar os grupos de trabalho e fazer a compilação dos dados. Da mesma forma que seus congêneres que tratam de outros temas de direitos humanos nas Nações Unidas, o relator especial para pessoas idosas receberia relatórios dos Estados-membros e ofereceria assistência e recomendações acerca da implementação do Plano de Ação Internacional de Madri sobre Envelhecimento. 
O relator seria responsável por promover os direitos das pessoas idosas ao identificar problemas e estratégias para solucioná-los. Ademais, teria o papel de evidenciar as melhores práticas dos Estados em relação à implementação do Plano de Ação de Madrid e apoiar o monitoramento governamental dessa implementação.

De acordo com o documento Fortalecendo os Direitos das Pessoas Idosas: A Caminho de uma Convenção, da organização não governamental Age Concern:

É necessário uma convenção dos direitos das pessoas idosas para assegurar que mulheres e homens idosos possam exercer os seus direitos. Com uma nova convenção nas Nações Unidas, e a assistência de um relator especial, os governos podem ter um quadro legal explícito, orientação e apoio que lhes permitam assegurar que os direitos das pessoas idosas sejam satisfeitos em nossas sociedades, cada vez mais, envelhecidas. ${ }^{31}$

\section{AÇÕES DO BRASIL NA TEMÁTICA DO IDOSO}

\section{I NACIONAIS}

Após a realização da I Assembleia Geral sobre Envelhecimento, em Viena, em 1982, a preocupação do governo brasileiro com a temática do Idoso ganhou força. A Política Nacional do Idoso, estabelecida em 1994 (Lei n. 8.842/1994), criou normas para os direitos sociais dos idosos, garantindo autonomia, integração e participação efetiva como instrumento de cidadania. Essa lei foi reivindicada pela sociedade, sendo resultado de inúmeras discussões e consultas ocorridas nos Estados, nas quais participaram idosos ativos, aposentados, professores universitários, profissionais da área de gerontologia e geriatria e várias entidades representativas desse segmento, que elaboraram um documento que se transformou no texto base da lei.

Da mesma forma, após a elaboração do Plano de Ação Internacional de Madri sobre o Envelhecimento, em 2002, a preocupação com a pessoa idosa volta a tornarse central para o Brasil. O Estatuto do Idoso (Lei n. 10.741/2003), que entrou em vigor no dia $1^{\circ}$ de janeiro de 2004, foi sancionado pelo presidente da República em outubro de 2003, após sete anos de tramitação no Congresso Nacional. Com ele, foram beneficiados mais de 16 milhões de brasileiros com 60 anos ou mais de idade.

Conforme Anna Cruz de Araújo Pereira da Silva enfatiza, "o Brasil confirmou a projeção da ONU, quando da vigência do Estatuto do Idoso apenas em 2004, mais de vinte anos após o Plano de Viena”. ${ }^{32}$

O Estatuto do Idoso, composto de 118 artigos, resgatou princípios constitucionais que garantem aos cidadãos direitos que preservam a dignidade, sem distinção de origem, raça, sexo e idade. Ele foi pautado nos princípios da absoluta prioridade ao idoso e na proteção integral do indivíduo. Os principais direitos assegurados pelo 
Estatuto do Idoso são o direito à saúde, ao trabalho, à igualdade, à educação, à participação política, ao desenvolvimento, à valorização de sua condição econômica, a viver livre da violência e ao meio ambiente acessível.

Em 2009, o III Plano Nacional de Direitos Humanos (PNDH-III) acolheu "a valorização da pessoa idosa e a promoção de sua participação na sociedade" como objetivo estratégico dentro da diretriz de "garantia da igualdade na diversidade", no sentido da universalização dos direitos em um contexto de desigualdades. ${ }^{33}$

Os direitos das pessoas idosas foram, assim, considerados oficialmente pelo Brasil como direitos humanos. Caso seja aprovada, uma convenção internacional dos direitos humanos da pessoa idosa seria recebida pela Constituição Federal brasileira de 1988, como direito fundamental e, poderia, conforme o artigo $5^{\circ}$, parágrafo $3^{\circ}$, atingir status de emenda constitucional, se aprovada por quórum especial.

Em 2010, instituiu-se o Fundo Nacional do Idoso com o objetivo de financiar os programas e as ações relativas ao idoso com vistas a assegurar os seus direitos sociais e criar condições para promover sua autonomia, integração e participação efetiva na sociedade. A criação do fundo significa dimensão pragmática da política nacional do idoso. ${ }^{34}$

\subsection{MERCOSUL}

Os países do Mercosul têm posições convergentes em relação à política internacional dos direitos das pessoas idosas. Afirmaram em julho de 2009, em comunicado conjunto, seu compromisso para com os direitos da pessoa idosa:

\section{Reiteraron su compromiso para promover, en el marco de las Naciones Unidas, el tratamiento de la temática de los Derechos de los Adultos Mayores, con el objeto de avanzar hacia la adopción de una Convención Internacional en la materia. En este contexto, se comprometieron a profundizar el diálogo interamericano sobre esta temática, de conformidad con la Resolución de la OEA sobre Derechos Humanos y Personas Mayores, aprobada en San Pedro de Sula, Honduras. ${ }^{35}$}

Ressalte-se que, em 2009, foi criado o grupo de trabalho da pessoa idosa nas discussões das reuniões de Altas Autoridades em Direitos Humanos do Mercosul e países associados (RAADH), consolidando a presença dos direitos humanos das pessoas idosas na pauta de discussões e cooperação regional. A RAADH ocorre, de maneira ordinária, uma vez por semestre, durante as presidências pro-tempore dos países integrantes do bloco. A continuidade das atividades do grupo de trabalho é fundamental para o posicionamento uniforme do bloco nas esferas internacionais.

\subsection{AMÉRICA LATINA}

O debate acerca da necessidade de um instrumento internacional vinculativo sobre 
os direitos humanos da pessoa idosa na América Latina extrapola as fronteiras dos países do Mercosul, ocorrendo nas reuniões da Comissão Econômica das Nações Unidas para a América Latina e Caribe (Cepal) e da Organização dos Estados Americanos (OEA).

A estratégia regional de implementação para a América Latina e o Caribe do Plano de Ação Internacional de Madri sobre o Envelhecimento foi adotada na I Conferência Regional Intergovernamental sobre Envelhecimento realizada em 2003 e ratificada na Resolução 604 do trigésimo período de sessões da Cepal. A estratégia regional teve como objetivo "promover os direitos humanos das pessoas idosas" e recomendou a elaboração de legislações específicas que definissem e protegessem esses direitos, em conformidade com os padrões internacionais e com a normativa aceita pelos Estados.

Em 2007, a Declaração de Brasília foi adotada durante a II Conferência Regional Intergovernamental sobre Envelhecimento na América Latina e no Caribe, quando os países participantes reafirmaram o compromisso de

não pouparem esforços para promover e proteger os direitos humanos e as liberdades fundamentais de todas as pessoas de idade, trabalhar na erradicação de todas as formas de discriminação e violência e criar redes de proteção das pessoas de Idade para fazer efetivos os direitos das pessoas Idosas. ${ }^{36}$

Especial atenção deve ser dada aos artigos 25 e 26 da Declaração de Brasília, cujos artigos tratam, respectivamente, da possibilidade de designar um relator especial que se encarregaria de zelar pela promoção e pela proteção dos direitos humanos das pessoas idosas, e a realização de consultas pertinentes entre os governos para a elaboração de uma convenção sobre os direitos humanos das pessoas idosas no âmbito das Nações Unidas.

Em setembro de 2008, realizou-se a I Reunião de Seguimento à Declaração de Brasília no Rio de Janeiro. O objetivo foi formular recomendações para o projeto de uma convenção internacional de direitos humanos para as pessoas idosas e medidas práticas para impulsionar a criação da convenção e a designação de um relator especial para o tema nas Nações Unidas. Dentre as principais recomendações da reunião, encontram-se: (i) que os governos apoiem incluir na resolução do $63^{\circ}$ período de sessões da ONU, um pedido ao Secretário Geral das Nações Unidas (SGNU) para que apresente um informe específico sobre os direitos das pessoas idosas durante o $64^{\circ}$ período de sessões de 2009; (ii) que os governos solicitem à Comissão de Assuntos Jurídicos do Conselho Permanente da OEA, sessão extraordinária para tratar da situação dos direitos humanos das pessoas idosas; e (iii) que a questão seja considerada nas intervenções dos representantes respectivos no Segmento de Alto Nível do Conselho de Direitos Humanos das Nações Unidas. 
Em maio de 2009, ocorreu a II Reunião de Seguimento à Declaração de Brasília, em Buenos Aires, cujo tema foi Hacia una Convención sobre los Derechos de las Personas Mayores, e se reiterou os objetivos da reunião precedente. Como resultado, obteve-se uma série de temas que poderiam fazer parte do texto da convenção, junto com a identificação de algumas ações futuras em curto prazo, dentre as quais destaca-se a seguinte: "Propõem-se que, durante esse processo, alianças sejam construídas entre os distintos países da região e fora dela. Para isso, se espera que na próxima reunião, no Chile, se discuta um documento mais acabado em termos técnicos e jurídicos".

Em outubro de 2009, ocorreu a III Reunião de Seguimento em Santiago do Chile, na sede da Cepal. Dentre as conclusões a que se chegaram está a recomendação de que Cepal elabore proposta estratégica para avançar nos conteúdos dos artigos 24 e 25 da Declaração de Brasília. ${ }^{37}$

Em maio de 2010, realizou-se a reunião do Comitê Especial da Cepal sobre População e Desenvolvimento, quando foi solicitado à Secretaria Executiva da Cepal que transmitisse ao Secretário Geral das Nações Unidas o interesse dos países da região em estabelecer um grupo de trabalho encarregado de liderar o processo de elaboração de um tratado internacional para proteger os direitos das pessoas idosas. ${ }^{38}$

Percebe-se, assim, o protagonismo e o avanço dos países da América Latina na elaboração de uma convenção internacional e a criação de um cargo de relator especial para o tema do idoso. Essas discussões devem avançar com a continuidade das reuniões de seguimento à Declaração de Brasília.

A dificuldade para a elaboração de uma convenção interamericana para os direitos humanos das pessoas idosas está na resistência das posições dos Estados Unidos e do Canadá, que argumentam haver outras discussões acerca de direitos humanos em pauta na OEA, prioritárias à temática do idoso por ordem de precedência. Além disso, os países latino-americanos enquadram-se em realidade socioeconômica diferenciada da experimentada pelos Estados Unidos e pelo Canadá. As demandas em relação aos direitos humanos dos idosos são, portanto, outras, o que dificulta a formação de um conceito regional amplo. Ressalte-se também que não há consenso entre os demais países da América Latina. O México, inicialmente favorável à convenção, hoje tem posições mais relutantes. Alguns países da América Central, Cuba e República Dominicana têm posições indecisas quanto ao assunto, e alguns países caribenhos de língua inglesa, holandesa e francesa sequer apareceram nas reuniões.

Entende-se, nesse sentido, em oportunidade próxima, que a discussão poderia ser levada ao âmbito da União de Nações Sul-Americanas (Unasul), que não contempla entre seus membros o Canadá e os Estados Unidos. Apesar de a União não apresentar foro específico para a discussão de direitos humanos, os países-membros já manifestaram em reiterados documentos o compromisso da Unasul com a defesa dos direitos humanos. 


\subsection{MULTILATERAL}

Nas Nações Unidas, as discussões sobre o envelhecimento ocorrem, ainda de maneira tímida, na Assembleia Geral, no Conselho Econômico e Social e no Conselho de Direitos Humanos. Foram feitos recomendações, estudos, resoluções, pactos, mas ainda não houve consenso sobre a necessidade de uma convenção internacional e de um cargo de relator especial para os direitos humanos das pessoas idosas.

O governo brasileiro defende que, antes da redação final do texto de uma Convenção Internacional dos Direitos da Pessoa Idosa, seria importante que grupos de trabalho regionais (constituídos por Estados e ONGs) levantassem diagnósticos acerca da situação dos idosos nos contextos nacional e regional. Mediante esses estudos, o consenso em relação à convenção deveria ser buscado no âmbito de alguns mecanismos regionais de integração.

A base conceitual da Convenção Internacional dos Direitos das Pessoas Idosas é a mudança de paradigma da perspectiva biológica e assistencial para a visão social dos direitos humanos, visando eliminar todas as formas de discriminação, entre outras, a discriminação por motivos de idade. É reconhecer também que as pessoas, à medida que envelhecem, devem desfrutar de uma vida plena, com saúde, segurança e participação ativa na vida econômica, social, cultural e política de suas sociedades. É fundamental o aumento do reconhecimento da dignidade dos idosos e a eliminação de todas as formas de abandono, abuso e violência, bem como a tarefa de incorporar eficazmente o envelhecimento nas estratégias, políticas e ações socioeconômicas. ${ }^{39}$

Aqueles que não apoiam a elaboração de uma convenção, entre outros fatores, baseiam-se nas dificuldades de adaptar políticas públicas nacionais a padrões internacionais que sejam modelos de implementação. Dentre essas dificuldades, Anna Cruz de Araújo Pereira da Silva atenta para o fato de que

a expectativa de vida tem superado em muitos anos o estabelecido para o percebimento de aposentadoria ou de pensões, o que é uma vitória sob muitos aspectos, mas certamente não para a contabilidade da seguridade social. De outra forma, o envelhecimento ativo permite a coexistência em geral tensa - de gerações no ambiente do trabalho ou, em pior hipótese, propicia a competição já petrificada em preconceitos. ${ }^{40}$

É necessário, assim, que uma convenção internacional atente-se às dificuldades de estabelecer padrões para a reforma previdenciária, além de promover o diálogo intergeracional, para não ser considerada nem principiológica, nem utópica. 
Outros argumentos contrários, de viés mais jurídico, apontam para o excesso de normas internacionais de direitos humanos. A hermenêutica normativa dos instrumentos existentes seria suficiente para o adequado tratamento das pessoas idosas.

A participação abrangente da sociedade civil é de suma importância no diálogo para a elaboração de uma convenção internacional, sobretudo porque a política do idoso tem reflexos na sociedade como um todo. Para alcançar-se o envelhecimento ativo e saudável, são necessárias políticas educacionais, previdenciárias, de saúde, entre outras tantas preocupações que dizem respeito à qualidade de vida das pessoas em qualquer idade. É ainda na juventude que se observa o cuidado preventivo para atingir o envelhecimento.

\section{CONCLUSÃO}

O envelhecimento da humanidade é, hoje, uma realidade em todos os continentes. Diante dessa mudança demográfica que deve orientar novas prioridades de políticas públicas é determinante que se atente para a estrutura normativa que irá pautar as novas relações entre os Estados e as sociedades.

Inicialmente, percebe-se um problema cultural a ser transposto, qual seja, o estigma do idoso. As sociedades contemporâneas, sobretudo as ocidentais, valorizam a juventude e entendem o idoso como inativo. Além de o idoso ter menos oportunidades de atuação, quer na economia, quer nos espaços sociais, muitas vezes ele é visto como fonte de problemas. Investir no idoso parece antagônico, pois a expectativa de vida é menor, comparada à de uma pessoa jovem. O idoso torna-se um custo a mais para as políticas públicas, o qual não se sabe se terá efeito multiplicador.

Essa visão acerca do idoso é base para o preconceito e a discriminação. Falta a promoção de educação, diálogo e políticas intergeracionais, que envolvam a pessoa idosa. Some-se a isso as dificuldades econômico-sociais experimentadas pelos países. Dados apontam que as pessoas idosas são as últimas a receberem cuidados em campos de refugiados. Mulheres idosas são privadas de direitos de herança em muitos países, sendo descartadas pelas sociedades.

No Brasil, percebe-se que, em muitos municípios, as economias locais giram em torno da fonte de renda dos idosos, sejam as aposentadorias ou os benefícios de prestação continuada. Muitos sustentam suas famílias e costumam ser explorados por elas, ou até mesmo violentados. A violência é também notada na negligência para com os idosos, muitas vezes abandonados e privados de suas moradias. Longe da família e de seu ambiente, o idoso perde suas referências, o que é substrato para mazelas psicológicas, com fortes efeitos sociais.

Diante do vigor das pessoas mais jovens, os idosos tornam-se atores hipossuficientes. É por isso que proteger os direitos das pessoas idosas é garantir condições de igualdade na sociedade. Esses direitos são contemplados na categoria de direitos 
humanos, não porque sejam especiais e diferentes de quaisquer outros direitos humanos, mas porque sua proteção merece atenção especial, para igualar-se à de qualquer outra pessoa. Infelizmente, é uma realidade mundial a violência contra os direitos humanos das pessoas idosas. Estes são atores que têm de enfrentar muitos obstáculos na sua participação como membros igualitários da sociedade.

A maior expectativa de vida, assim, é positiva para as sociedades, mas também é fonte de novos desafios. O idoso deve ser visto como ganho social. A elaboração de uma convenção internacional e a criação de um cargo de relator especial das Nações Unidas para os direitos humanos dos idosos são objetivos fundamentais para completar, por meio de obrigações peremptórias e de maior acompanhamento institucional de políticas para os idosos, a proteção do desenvolvimento natural do ser humano.

Tendo o Brasil se beneficiado dessa revolução demográfica, deve atuar para garantir um envelhecimento mais ativo, digno e humano. Percebe-se que o País vem acompanhando o desenvolvimento da temática do idoso nas esferas internacionais e nacionais. O esforço em favor de uma convenção internacional e de um cargo de relator especial deve acompanhar a política internacional do Brasil em relação aos direitos humanos da pessoa idosa. A recepção de novas normas internacionais referentes à temática do idoso deve ganhar relevância de norma constitucional, haja vista referir-se a direito fundamental de todos os brasileiros.

: ARTIGO APROVADO (21/01/2011) : RECEBIDO EM 13/07/2010

NOTAS

1 PNDH-3, Secretaria Especial de Direitos Humanos da Presidência da República.

2 PPA 2008-2011, Anexo III, Órgãos Responsáveis por Programas. Disponível em: <http://www.planejamento.gov.br/>. Acesso em: 11 fev. 2010.

3 Os novos velhos. O Globo, 8 fev. 2010.

4 Nações Unidas. World Population Ageing, 2009. Nova York. Departamento de Assuntos Econômicos e Sociais, 2009.

5 World Population Ageing, 2009. Economics and Social Affairs. Disponível em: <http://www.un.org/esa/population/publications/WPA2009/WPA2009_WorkingPaper.pdf >.

6 Idem, ibidem. 
7 Cepal/Celadi (2007). Informe sobre a aplicação da Estratégia regional de implementação para América Latina e Caribe do Plano de Ação Internacional de Madri sobre o Envelhecimento. LC/L. 2749 (CRE-2/3). Santiago, Chile, 2007.

8 Pesquisa Nacional de Amostra Domiciliar (PNAD), IBGE. Síntese dos Indicadores Sociais - Uma Análise das Condições de Vida da População Brasileira 2008.

9 O papel da Onu na elaboração de uma cultura gerontológica. In: A terceira idade: Estudos sobre envelhecimento. São Paulo: Sesc, V.1 18 n. 39, 2007.

10 Fortalecendo os direitos das pessoas idosas: a caminho de uma convenção. Tradução de Maria Helena J. M. de Macedo Fragoso. Disponível em: <http://www.ageconcern.org.uk/AgeConcern/UN-convention-older-rightsjuly09.asp >. Acesso em: 8 mar. 2010.

11 HUENCHUAN, Sandra; MORLACHETTI, Alejandro. Análisis de los instrumentos internacionales y nacional de derechos humanos de las personas mayores. Celade, Divisão de População da Cepal, C/G.2300-P. Santiago, Chile. Revista Notas de Población, n. 81, 2006.

12 Fortalecendo os direitos das pessoas idosas: A caminho de uma convenção. Tradução de Maria Helena J. M. de Macedo Fragoso. Disponível em: <http://www.ageconcern.org.uk/AgeConcern/UN-convention-older-rightsjuly09.asp>. Acesso em: 8 mar. 2010.

13 Por que é tempo de uma Convenção dos Direitos das Pessoas Idosas? HelpAge International, fev. 2010. Tradução de Maria Helena J. M. de Macedo Fragoso.

14 O papel da Onu na elaboração de uma cultura gerontológica. In: A terceira idade: Estudos sobre envelhecimento. São Paulo: Sesc, V.1 18 n. 39, 2007.

15 HUENCHUAN, Sandra; MORLACHETTI, Alejandro. Op. cit.

16 NAÇÕES UNIDAS. Os direitos econômicos, sociais e culturais das pessoas idosas. Observação geral n. 6. E/C, 16 dez. 1995. Ver. 1. Genebra, Comitê de Direitos Econômicos, Sociais e Culturais.

17 Idem, ibidem.

18 HUENCHMAN, Sandra; ALEJANDRO, Morlachetti. Op. cit.

19 Idem. Derechos sociales y envejecimiento: modalidades y perspectivas de respecto y garantía em América, Notas de población n. 85, Celad, Divisão de População da Cepal, LC/G., 2300 p., Santiago, Chile, 2007.

20 BOYLE, A. E. Some reflections on relationship of Treaties and Soft Law, 1999.

21 Por que é tempo de uma Convenção dos Direitos das Pessoas Idosas? HelpAge International, fev. 2010. Tradução de Maria Helena J. M. de Macedo Fragoso.

22 NAÇÕES UNIDAS. Resolución 3137 (XXVIII). Cuestión de las personas de edad y los ancianos, 14 dez. 1973.

23 NAÇÕES UNIDAS. Resolución 37/51. Cuestión del Envejecimiento, 3 dez. 1982.

24 O Papel da Onu na Elaboração de uma Cultura Gerontológica. In: A terceira idade: Estudos sobre envelhecimento. São Paulo: Sesc, V.l 18 n. 39, 2007.

25 Nações Unidas. Resolución 46/91Ejecución del Plano de Acción Internacional sobre el Envejecimiento y actividades conexas, $16 \mathrm{dez} .1991$.

26 NAÇÕES UNIDAS. Plano de Ação Internacional de Madri sobre o Envelhecimento, 2002.

27 World Population Ageing, 2009. Economics and Social Affairs. Disponível em: <http://www.un.org/ 
esa/population/publications/WPA2009/WPA2009_WorkingPaper.pdf>.

28 O papel da Onu na elaboração de uma cultura gerontológica. In: A terceira idade: Estudos sobre envelhecimento. São Paulo: Sesc, V.1 18 n. 39, 2007.

29 A/HRC/AC/4/CRP.1 The necessity of a human rights approach and effective United Nations mechanism for the human rights of the older person. Working paper prepared by Ms. Chinsung Chung, member of the Human Rights Council Advisory Committee.

30 Comitê para a Eliminação da Discriminação contra a Mulher. Grupo de trabalho anterior ao $44^{\circ}$ período de sessões, 20 jul. a 7 ago. 2009.

31 Fortalecendo os Direitos das Pessoas Idosas: A Caminho de uma Convenção. 2010. Disponível em: <http://www.ageconcern.org.uk/AgeConcern/UN-convention-older-rights-july09.asp>. Acesso em: 8 mar. Tradução de Maria Helena J. M. de Macedo Fragoso.

32 O papel da Onu na elaboração de uma cultura gerontológica. In: A terceira idade: Estudos sobre envelhecimento. São Paulo: Sesc, V.1 18 n. 39, 2007.

33 PNDH-3. Secretaria Especial de Direitos Humanos da Presidência da República.

34 Lei n. 12.213, 20 jan. 2010.

35 Comunicado conjunto de los Presidentes de los Estados Partes del Mercosur y Estados Asociados. Disponível em: <http://www.mercosul.gov.br/comunicados/2009/comunicado-conjunto-de-los-presidentes-de-los-estadospartes-del-mercosur-y-estados-asociados/?searchterm=adultos\%20mayores $>$. Acesso em: 8 mar. 2010.

36 Declaração de Brasília, LC/G.2359, jan. 2008.

37 Conclusiones de la III Reunión de seguimiento de la Declaración de Brasília. Disponíverl em: <http://www.ampid.org.br/Docs_ID/Conv_PessoaIdosa.php\#bsb3>. Acesso em: 8 mar. 2009.

38 Acordos População e Desenvolvimento: Temas Prioritários para 2010-2012. Comitê Especial da Cepal sobre População e Desenvolvimento. Santiago, Chile, 12 a 14 de mai.2010.

39 Justificativa para uma Convenção Específica sobre os Direitos da Pessoa Idosa. Iadya Gama Maio. Disponível em: <http://www.ampid.org.br/Docs_ID/Conv_PessoaIdosa.php\#justifica>. Acesso em: 11 fev. 2010.

40 O Papel da Onu na Elaboração de uma Cultura Gerontológica. In: A terceira idade: Estudos sobre envelhecimento. São Paulo: Sesc, V.1 18 n. 39, 2007.

\section{Maria Helena de Aguiar Notari}

Rua Rocha, $233,11^{\circ}$ andar
Bela Vista - $01330-000$
São Paulo - SP - Brasil
revistadireitogvlafgv.br
BACHAREL EM RELAÇÕES INTERNACIONAIS PELA UnB

Oficial dE ChANCELARIA

EX-assessora Internacional do Programa Nacional para os Direitos dos IDOSOS da SECRETARIA ESPECIAL DE Direitos Humanos da PREsidênCIA da República, 2009 
276 : A INSERÇÃO DO BRASIL NA POLÍTICA INTERNACIONAL DE DIREITOS HUMANOS DA PESSOA IDOSA

Rua Rocha, 233, $11^{\circ}$ andar Bela Vista - 01330-000 São Paulo - SP - Brasil revistadireitogvafgv.br

\section{Maria Helena J. M. de Macedo Fragoso} Advogada, Especialista em Relações InTERnacionais PELO Programa Santiago Dantas (Unesp, Unicamp, PUC-SP)

OFICIAL DE CHANCELARIA

Assessora INTERnACIONAL DA COORDENAÇÃo GERAL dOS Direitos do Idoso, Secretaria de Direitos Humanos DA PRESIDÊnCIA DA REPÚBLICA 